(2) Open Access Full Text Article

\title{
Implantation of a Trifocal Intraocular Lens in High Myopic Eyes with Nasal-Inferior Staphyloma
}

This article was published in the following Dove Press journal:

Clinical Ophthalmology

\author{
Belén Alfonso-Bartolozzi' \\ Eva Villota' \\ Álvaro Fernández-Vega- \\ González' \\ Luis Fernández-Vega-Cueto (iD) ' \\ Álvaro Fernández-Vega' \\ José F Alfonso (D) ${ }^{1,2}$ \\ 'Fernández-Vega Ophthalmological \\ Institute, Oviedo, Spain; ${ }^{2}$ Surgery \\ Department, School of Medicine, \\ University of Oviedo, Oviedo, Spain
}

Correspondence: José F Alfonso Instituto Oftalmológico Fernández-Vega, Avda. Dres. Fernández-Vega II4, Oviedo, 33012 Spain

Tel +34985 245533

Fax +34985 233288

Email j.alfonso@fernandez-vega.com
Purpose: To assess visual outcomes in high myopic eyes with nasal-inferior staphyloma implanted with a pseudophakic trifocal intraocular lens (IOL).

Methods: We retrospectively analyzed the visual outcomes of 50 eyes of 45 patients who had cataract surgery after AT LISA trifocal IOL implantation. Twenty-five eyes diagnosed with posterior staphyloma (nasal-inferior, type IV and V), and 25 eyes as long eyes. Uncorrected distance visual acuity (UDVA) and corrected distance visual acuity (CDVA) values were used to assess the efficacy and safety of the surgery. Refraction and defocus curves were also evaluated at 6 months.

Results: No intra- or post-operative problems occurred during the 6 months of follow-up. After the surgery, the mean Snellen decimal UDVA ranged from 0.50 to 1.00 , and CDVA from 0.60 to 1.00 for both groups. CDVA was 0.91 and 0.74 for the long eye and nasalinferior staphyloma groups, respectively. Efficacy and safety indexes were 1.22 and 1.32 for the long eye, and 1.26 and 1.43 for the nasal-inferior staphyloma group, respectively. All eyes of both groups showed a postoperative spherical equivalent within $\pm 1.00 \mathrm{D}$. The long eye group showed the highest percentage of spherical equivalent between $-0.13 \mathrm{D}$ and $+0.13 \mathrm{D}(56 \%)$ and the nasal-inferior staphyloma group was between $-0.51 \mathrm{D}$ and $-0.14 \mathrm{D}$ $(40 \%)$.

Conclusion: The outcomes of the present study show that a trifocal IOL provides good visual acuity in high myopic eyes, being worse for nasal-inferior staphyloma eyes. The degree of tilt of the macular plane is related with the expected visual acuity.

Keywords: high myopia, multifocal intraocular lens, phacoemulsification, staphyloma

\section{Introduction}

The population affected by myopia is increasing, and in some areas, the prevalence in young adults is near to $90 \% .^{1}$ About one-fifth of the myopic population has high myopia (more than -6D). ${ }^{1}$ Posterior staphyloma in high myopic eyes is related to different complications that may affect the visual function of these patients. ${ }^{2,3}$ The prevalence of posterior staphyloma varies depending on the study and the population analysed. For example, it has been found a $0.7 \%$ in the Blue Mountains Eye Study ${ }^{4}$ ( $n=3654$, age $\geq 49$ years), a $0.8 \%$ in the Handan Eye Study ${ }^{5}(n=6830$, age $\geq 30$ years), a $1.6 \%$ in the Beijing Eye Study $^{6}$ ( $n=4439$, age $\geq 40$ years), a $0.1 \%$ in Singaporean children $^{7}\left(n=1227\right.$, age $12-16$ years) or a $10.7 \%$ in Saudi Arabia cataract patients ${ }^{8}$ ( $n=629$, age $\geq 40$ years). A recent study carried out by Numa et $\mathrm{al}^{9}$ indicated that the calculated prevalence in highly myopic eyes varies from $19 \%$ to $90 \%$. In this study they found a $10.9 \%$ in their highly myopic eyes $(n=395)$ and the prevalence of posterior staphyloma increased with advancing age: from $2.7 \%$ for $35-50$ years, $9.2 \%$ for $50-59$ 
years, $21.2 \%$ for $60-69$ years, to $43.6 \%$ for $70-79$ years. Then, the combination of high myopia and age is a key factor for staphyloma presence.

In addition, it has been reported that there is an evidence of an association between myopia and incident cataract and cataract surgery. ${ }^{10,11}$ Taking account of these premises, surgeons should be aware of the possibilities to offer their high myopic patients for cataract surgery. Despite the use of multifocal intraocular lenses (IOLs) in high myopic eyes may be considered controversial, specifically due to retinal complications that difficult any posterior treatment or reduce the visual performance of these lenses, some publications indicated the good outcomes. Alfonso et $\mathrm{al}^{12}$ assessed the outcomes found in 76 high myopic eyes (10-14.50 D IOL power, and 43-73 years) with the AcrySof ReSTOR IOL concluding that this lens provided good visual acuity and contrast sensitivity. Wang et $\mathrm{al}^{13}$ found a high level of spectacle independence and satisfaction among patients with high myopia with the AcrySof ReSTOR IOLs (48 eyes with 6.5-14 D IOL power, and 45-68 years). Martiano and Cochener $^{14}$ evaluated 52 high myopic eyes with the AT LISA bifocal IOL showing favourable results at 6 years (26.54-30.7 mm axial length, 0-14 D IOL power, and 49-69 years). Ogawa et $\mathrm{al}^{15}$ demonstrated good visual acuity outcomes in 32 eyes implanted with the ZMA00/ ZMB00 IOL (26.06-29.24 $\mathrm{mm}$ axial length, and 40-71 years). And recently, $\mathrm{Zhu}$ et $\mathrm{al}^{16}$ found in 28 eyes implanted with the ZMB00 IOL good visual acuity comparable to emmetropic eyes but reporting that the myopic eyes presented inferior decentration and a decrease visual quality ( $>24.5 \mathrm{~mm}$ axial length, and a mean of 68.17 \pm 8.24 years).

Based on these previous studies and considering that the use of multifocal IOLs in high myopic eyes is a viable option, the purpose of this study is to evaluate the visual performance in high myopic eyes with nasal-inferior staphyloma implanted with a trifocal IOL. A control group of long eyes without staphyloma was included for comparison.

\section{Methods}

We retrospectively examined 50 eyes of 45 patients who had lensectomy with a multifocal IOL implantation at the Fernández-Vega Ophthalmological Institute (Oviedo, Spain) between March 2013 and November 2017. All patients aimed to correct both refractive error and presbyopia. Informed consent was obtained from all patients after the nature and possible consequences of the study were explained. This was a retrospective study and a standard clinical surgery was performed in our center. Patients signed a specific consent form that covers their privacy and the data can be used for research clinical purposes following the Declaration of Helsinki, and which meets the requirements of the Fernández-Vega Universitary Institute review board.

All patients, before IOL implantation, were submitted to a complete ophthalmologic examination. This examination considered the measurement of the uncorrected distance visual acuity (UDVA), corrected distance visual acuity (CDVA), defocus curve, ocular refraction, slit-lamp examination, corneal topography, anterior chamber depth and pachymetry (Orbscan II; Bausch \& Lomb, Rochester, NY), ocular biometry (IOLMaster 500; Carl Zeiss-Meditec, Jena, Germany) and posterior optical coherence tomography (OCT, 3D OCT-2000, Topcon, the Netherlands). Inclusion criteria were age between 20 and 80 years, axial length $\geq 26 \mathrm{~mm}$, and patient interest to no longer wear any form of spectacle or contact lens correction. Exclusion criteria included $>3.00 \mathrm{D}$ of corneal astigmatism, history of glaucoma or corneal disease, previous corneal or intraocular surgery, abnormal iris, pupil deformation, neuroophthalmic diseases, and history of prior ocular inflammation.

Twenty-five eyes were diagnosed with nasal-inferior staphyloma and 25 eyes as long eyes without staphyloma. Curtin in 1977 differentiated posterior staphyloma into 10 types, both primary and composed. ${ }^{17}$ Later, Ohno-Matsui et al ${ }^{18}$ using three-dimensional magnetic resonance imaging (3D-MRI) and ultra-widefield fundus imaging proposed another classification into 6 types, based on the shape, location and shape of the staphyloma. Shinohara et $\mathrm{al}^{19}$ have recently concluded that widefield OCT may replace 3D-MRI in assessing posterior staphylomas. In our case, patients were examined with posterior OCT with 6 radial scans on the $6-\mathrm{mm}$ central macular area and those diagnosed with posterior staphyloma were classified as type IV and V according to the Ohno-Matsui et al ${ }^{18}$ classification. In addition, we also measured the macula plane tilt in staphyloma eyes. Macula plane tilt was defined as the flat surface that contains the macula towards the 6 scans of the OCT (at 9, 10, 11, 12, 1 and 2 hrs). The largest tilted plane indicates the direction of the staphyloma, and we subclassified them according to the tilt: $<30$ degrees, and $>30$ degrees. Figure 1 shows an example of the classification. It is expected that a large value of tilt may be correlated with a worst visual acuity.

All surgeries in this study were operated by phacoemulsification with the Centurion Vision System (Alcon, Fort Worth, TX) using topical anaesthesia and a clear corneal incision of $2.2-\mathrm{mm}$ on the steep-axis by an experienced 

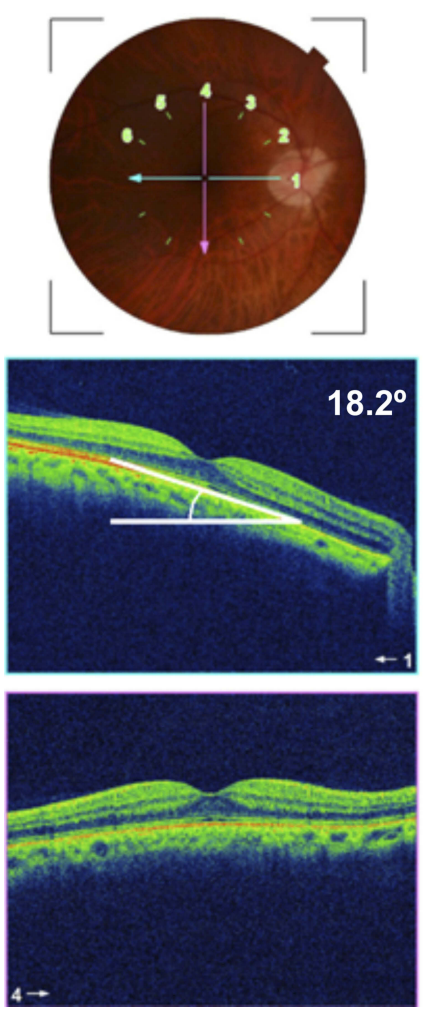
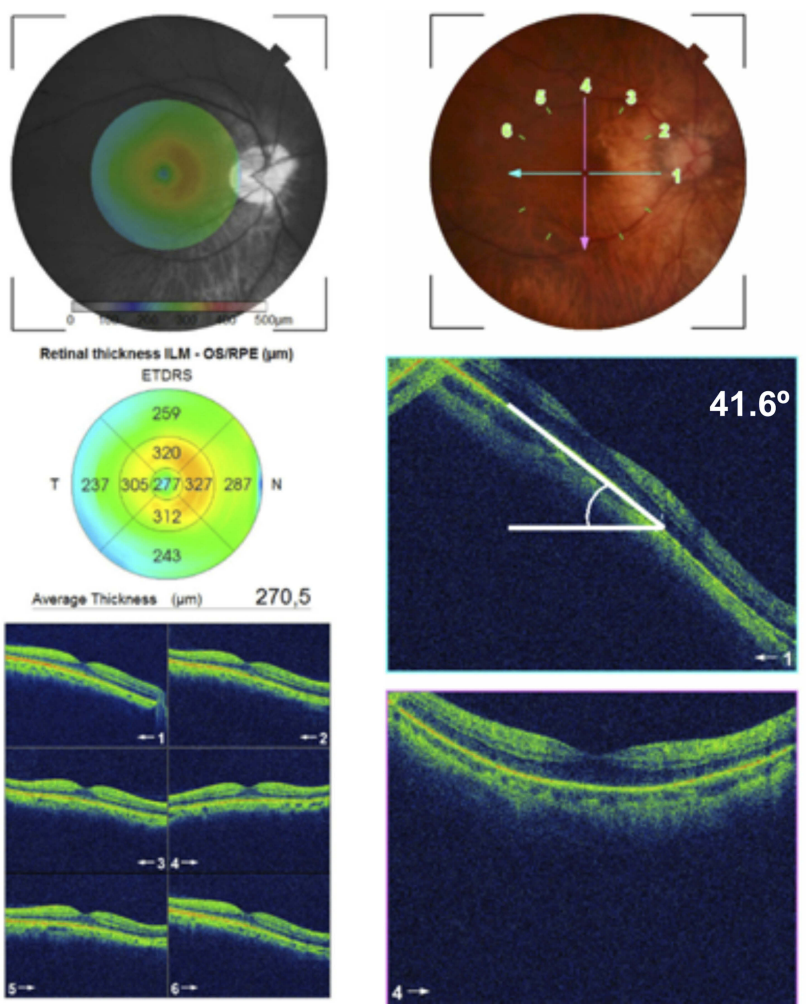

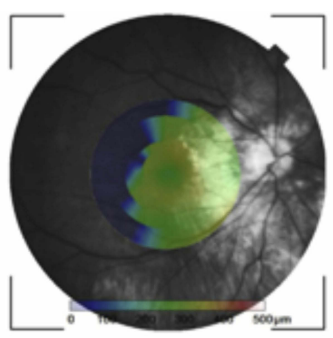

Retinal thickness ILM - RPE ( $\mu \mathrm{m})$
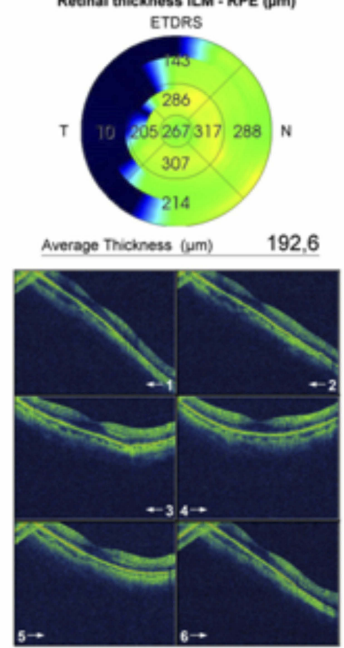

Figure I Classification of nasal-inferior staphyloma according to the macular plane tilt. From left to right: $<30$ degrees, and $>30$ degrees.

surgeon (J.F.A.) using the Callisto system (Carl Zeiss Meditec AG, Germany). All eyes were submitted to femtosecond laser-assisted lens surgery using the LenSx platform (Alcon, Fort Worth, TX) to perform the anterior capsulotomy and fragment of the nucleus, and a 14C Morcher capsular tension ring (CTR) was implanted. The SRK/T formula was used for IOL power calculation. The targeted refraction was emmetropia. The multifocal IOL implanted was the AT LISA tri 839MP (Carl Zeiss Meditec, Dublin, CA). This is a single-piece aspheric diffractive multifocal IOL with a $6.0-\mathrm{mm}$ biconvex optic, an overall diameter of $11.0 \mathrm{~mm}$ (0-degree haptic angulation). The optic design of the IOL combines a central trifocal zone of 4.34-mm diameter with a bifocal zone on the periphery from 4.34 to $6.0 \mathrm{~mm}$. In the central zone, the IOL provides a near addition of $+3.33 \mathrm{D}$ and an intermediate addition of $+1.66 \mathrm{D}$ at the IOL plane. The incident light is distributed asymmetrically with $50 \%, 20 \%$, and $30 \%$ to distance, intermediate, and near foci, respectively. The IOL has an aspheric profile to correct positive spherical aberration of the cornea. The optic is made of foldable hydrophilic acrylate (refractive index 1.46 ) with $25 \%$ water content and hydrophobic surface properties. The hydrophobic surface of the lens has a 360-degree square edge to reduce posterior capsule opacification. The IOL power varies from 0.00 to +32.00 $\mathrm{D}$ in $0.50 \mathrm{D}$ steps.

There were no complications in any of the cases after phacoemulsification and IOL implantation. Patients were scheduled for clinical evaluation preoperatively and 1 day, and 1, 3 and 6 months postoperatively. The preoperative and postoperative visual acuity outcomes were evaluated and possible adverse complications were assessed. The efficacy index (defined as the ratio between postoperative UDVA and preoperative CDVA measured in Snellen decimal) and the safety index (defined as the ratio between postoperative and preoperative CDVA) were also calculated. All patients were evaluated for 6 months. One optometrist performed all examinations at 6 months after implantation, and data analysis was performed using Microsoft Excel (Microsoft Corporation, USA) and SPSS statistical software version 24 (IBM Corp, USA). The normality of all data sets was evaluated by means of the Shapiro-Wilk test and $t$-test or Wilcoxon signed rank test was used accordingly. The statistical significance limit was set to $\mathrm{P}<0.05$ in all cases.

\section{Results}

Fifty eyes of 45 patients participated in this study. Table 1 shows the preoperative characteristics of the eyes evaluated. 
Table I Preoperative Characteristics of the Patients Submitted to Study (Mean, SD and Range)

\begin{tabular}{|l|l|l|l|}
\hline & $\begin{array}{l}\text { Long Eye } \\
\text { (n= 25) }\end{array}$ & $\begin{array}{l}\text { Nasal-Inferior } \\
\text { Staphyloma } \\
\text { (n= 25) }\end{array}$ & P value \\
\hline Age (years) & $\begin{array}{l}54.48 \pm 10.60 \\
(20 \text { to 69) }\end{array}$ & $\begin{array}{l}54.33 \pm 10.17 \\
\text { (31 to } 71)\end{array}$ & 0.47 \\
\hline $\begin{array}{l}\text { Preoperative sphere } \\
\text { (D) }\end{array}$ & $\begin{array}{l}-9.41 \pm 3.69 \\
(-3.00 \text { to }-18.5)\end{array}$ & $\begin{array}{l}-11.04 \pm 3.30 \\
(-4.50 \text { to }-20.00)\end{array}$ & 0.05 \\
\hline $\begin{array}{l}\text { Preoperative cylinder } \\
\text { (D) }\end{array}$ & $\begin{array}{l}-0.71 \pm 0.50 \\
(0.00 \text { to }-1.75)\end{array}$ & $\begin{array}{l}-0.86 \pm 0.88 \\
(0 \text { to }-3.00)\end{array}$ & 0.16 \\
\hline Preoperative CDVA & $\begin{array}{l}0.74 \pm 0.20 \\
(0.30 \text { to } 1.00)\end{array}$ & $\begin{array}{l}0.59 \pm 0.24 \\
(0.20 \text { to } 1.00)\end{array}$ & 0.01 \\
\hline Preoperative KI (D) & $\begin{array}{l}42.97 \pm 0.97 \\
(41.00 \text { to } 44.50)\end{array}$ & $\begin{array}{l}43.65 \pm 1.64 \\
(41.00 \text { to } 47.75)\end{array}$ & 0.04 \\
\hline Preoperative K2 (D) & $\begin{array}{l}43.67 \pm 1.23 \\
(41.00 \text { to } 46.00)\end{array}$ & $\begin{array}{l}44.56 \pm 1.63 \\
(42.25 \text { to } 48.00)\end{array}$ & 0.02 \\
\hline Axial length (mm) & $\begin{array}{l}27.59 \pm 1.08 \\
(26.35 \text { to } 29.83)\end{array}$ & $\begin{array}{l}27.94 \pm 0.99 \\
(26.10 \text { to } 29.90)\end{array}$ & 0.10 \\
\hline IOL power (D) & $\begin{array}{l}9.78 \pm 3.59 \\
(2.00 \text { to 15.50) }\end{array}$ & $\begin{array}{l}7.73 \pm 3.10 \\
(2.50 \text { to 14.00) }\end{array}$ & 0.02 \\
\hline
\end{tabular}

Abbreviations: D, diopters; CDVA, corrected-distance visual acuity (Snellen decimal); IOL, intraocular lens.

As previously indicated, phacoemulsification and AT LISA tri 839MP implantation were performed successfully in all eyes and no intra and post-operative problems occurred during the 6 months of follow-up.

On average, the results that we have obtained at 6 months of follow-up reveal good outcomes for UDVA and CDVA. Table 2 shows the detailed values for the different groups assessed. Specifically, mean UDVA values ranged from 0.50 to 1.00 Snellen decimal, and mean CDVA values from 0.60 to 1.00 Snellen decimal. The best UDVA was obtained in the long eye group (0.91) and the worst UDVA was for the nasalinferior staphyloma group (0.74). Similar pattern was obtained for the CDVA ( 0.98 vs 0.84 ). There were statistically significant differences between groups both for UDVA and CDVA ( $<<0.01$ ), showing better outcomes for the long eye group. In relation to the efficacy and safety indexes, both groups revealed good outcomes. When the nasal-inferior staphyloma group was analysed as a function of the tilt, we found differences between the group of $<30$ degrees (10 eyes), and the group of $>30$ degrees ( 15 eyes). CDVA was 0.93 for the $<30$ degrees group and 0.79 for the group of $>30$ degrees $(p<0.01)$. So, larger values of tilt are associated with worse CDVA.

Figure 2A shows the postoperative change in CDVA for the two groups. Only 3 eyes lost 1 line of CDVA, being 1 eye
Table 2 Postoperative Visual Acuity and Refraction of the Patients Submitted to Study (Mean, SD and Range)

\begin{tabular}{|l|l|l|l|}
\hline & $\begin{array}{l}\text { Long Eye } \\
(\mathbf{n}=25)\end{array}$ & $\begin{array}{l}\text { Nasal-Inferior } \\
\text { Staphyloma }(\mathbf{n}=\mathbf{2 5})\end{array}$ & P value \\
\hline UDVA & $\begin{array}{l}0.91 \pm 0.10 \\
(0.70 \text { to } 1.00)\end{array}$ & $\begin{array}{l}0.74 \pm 0.15 \\
(0.50 \text { to } 1.00)\end{array}$ & $<0.01$ \\
\hline CDVA & $\begin{array}{l}0.98 \pm 0.04 \\
(0.90 \text { to } 1.00)\end{array}$ & $\begin{array}{l}0.84 \pm 0.11 \\
(0.60 \text { to } 1.00)\end{array}$ & $<0.01$ \\
\hline Sphere (D) & $\begin{array}{l}-0.14 \pm 0.23 \\
(0.00 \text { to }-0.75)\end{array}$ & $\begin{array}{l}-0.11 \pm 0.39 \\
(1.00 \text { to }-0.75)\end{array}$ & 0.50 \\
\hline Cylinder (D) & $\begin{array}{l}-0.12 \pm 0.21 \\
(0.00 \text { to }-0.50)\end{array}$ & $\begin{array}{l}-0.20 \pm 0.29 \\
(0.00 \text { to }-1.00)\end{array}$ & 0.10 \\
\hline Efficacy index & 1.22 & 1.26 & - \\
\hline Safety index & 1.32 & 1.43 & - \\
\hline
\end{tabular}

Abbreviations: UDVA, uncorrected distance visual acuity (Snellen decimal); CDVA, corrected-distance visual acuity (Snellen decimal); D, diopters.

for the long eye group and 2 eyes for the nasal-inferior staphyloma group. On average, the highest percentage of eyes gained 3 or more lines of CDVA followed by a gain of 2 lines. Figure 2B shows the change in CDVA considering only the nasal-inferior staphyloma group and the degree of tilt, where it is possible to observe that better outcomes are found for the $<30$ degrees subgroup.

Figure $2 \mathrm{C}$ shows the cumulative proportion of eyes having a given CDVA value, both preoperatively and at 6 months postoperatively. The postoperative CDVA was 20/20 in 20 eyes $(80 \%)$ and in 5 eyes $(20 \%)$ for the long eye and nasalinferior staphyloma groups, respectively. The long eye group achieved a $100 \%$ of eyes with a cumulative CDVA of 20/25 and the nasal-inferior staphyloma a $100 \%$ of eyes with a cumulative CDVA of 20/32.

In relation to refraction, all eyes of both groups showed both a postoperative spherical equivalent within $\pm 1.00 \mathrm{D}$ (see Figure 2D). The long eye group showed the highest percentage of spherical equivalent between $-0.13 \mathrm{D}$ and $+0.13 \mathrm{D}(56 \%)$, and the nasal-inferior staphyloma group between -0.51 and $-0.14 \mathrm{D}$ (40\%). Defocus curves for both groups are depicted in Figure 3 were two peaks of maximal visual acuity were observed.

\section{Discussion}

High myopic patients should be carefully evaluated before any intraocular lens implantation surgery. Retinal alterations, specifically macular degeneration, should be discarded since these conditions may affect the visual outcomes after IOL implantation. A recent review carried out by Srinivasan et $\mathrm{al}^{20}$ 
A

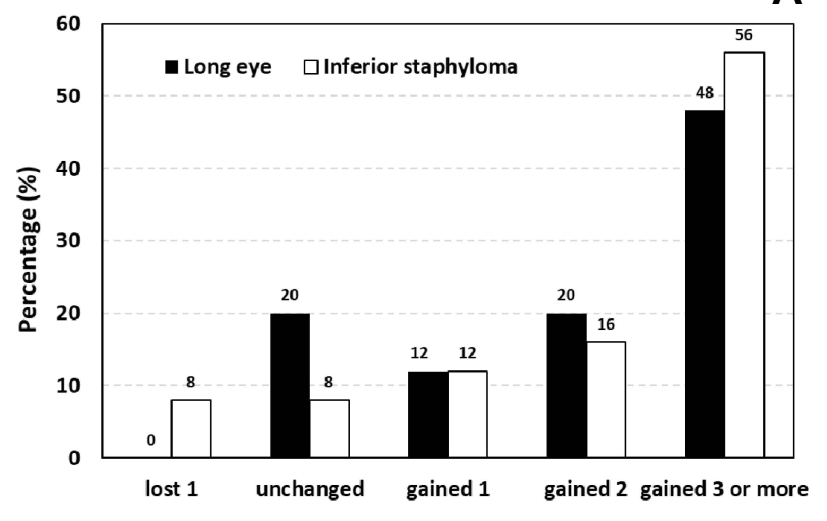

C

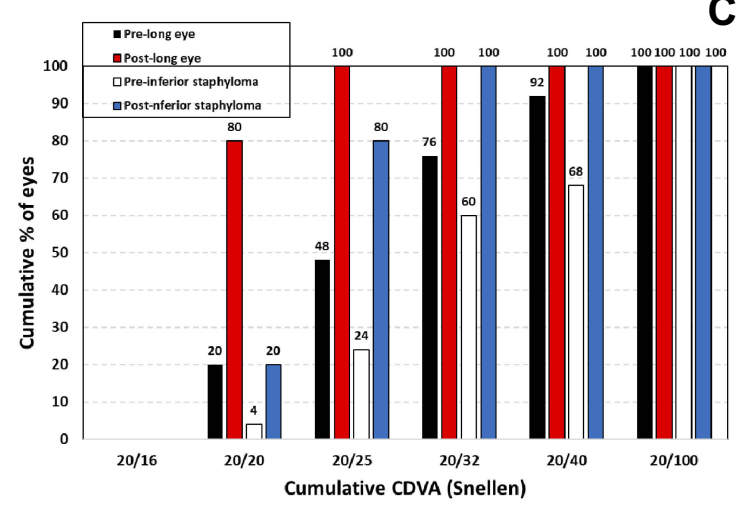

B

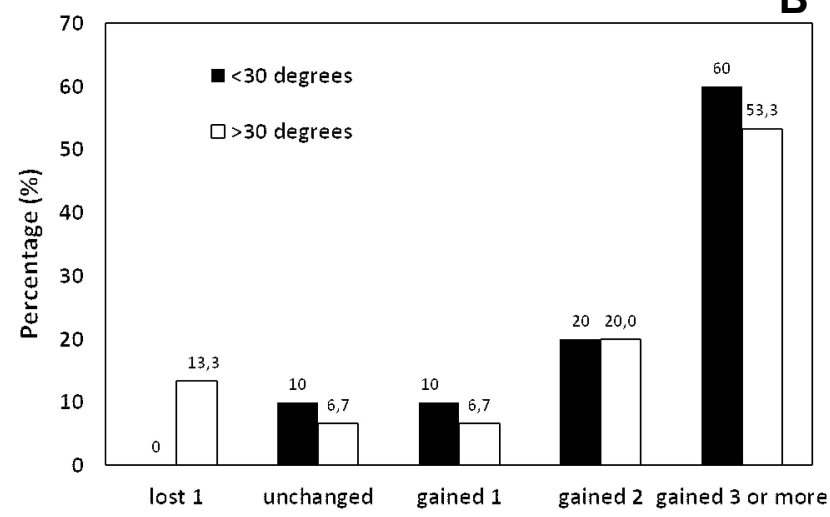

D

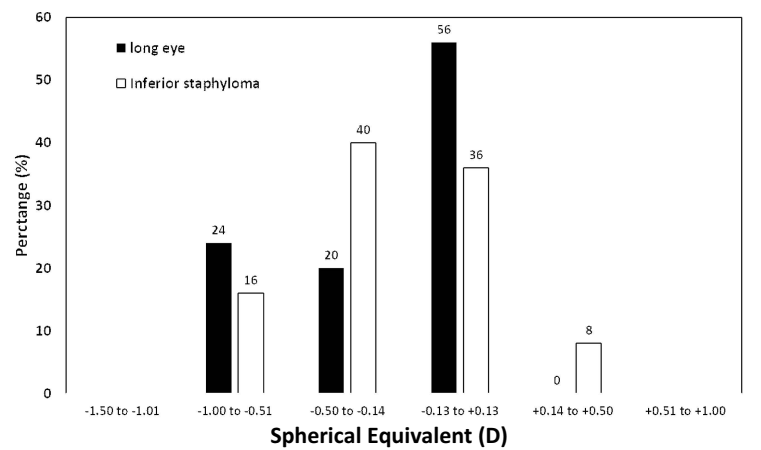

Figure 2 Postoperative changes in best-corrected distance visual acuity (CDVA) at 6 months postoperatively for the two groups evaluated (A) Postoperative changes in best-corrected distance visual acuity (CDVA) at 6 months postoperatively for the nasal-inferior staphyloma group as a function of the degree of tilt: $<30$ and $>30$ degrees (B) Cumulative corrected distance visual acuity (CDVA) before and after surgery for the two groups evaluated (C) Postoperative spherical equivalent refraction for the two groups evaluated (D)

AT LISA Tri / with \& without staphyloma

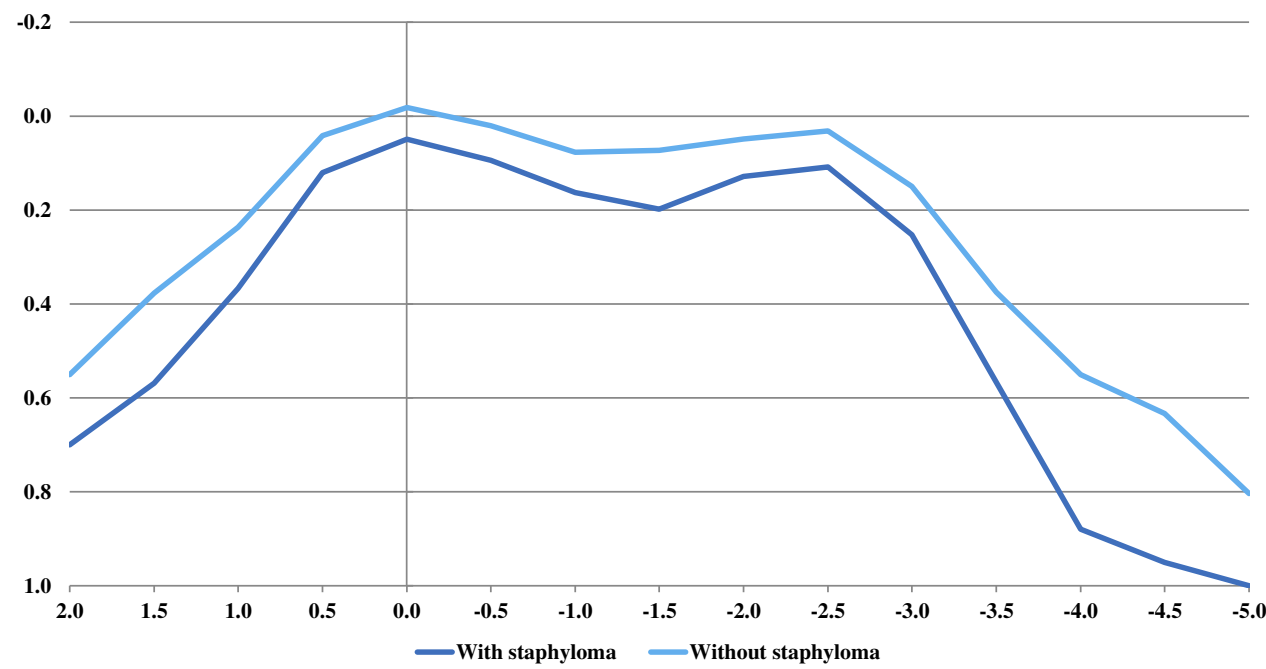

Figure 3 Defocus curve (logMAR visual acuity versus defocus) for the two groups evaluated.

assessing safety and effectiveness in treating high myopia with modern phacoemulsification indicates that despite high myopia is an independent risk factor for retinal detachment there is a lesser risk considering recent publications. Patients suffering from high myopia, which is mainly characterized by excessive axial length, may show reduced visual acuity. 
However, as we have introduced, the use of multifocal IOLs for presbyopia correction in eyes with long axial lengths has been increasing due to the good outcomes reported previously by several authors using different IOL models. ${ }^{12,13,15,16}$

Our results revealed good visual acuity outcomes for both groups of patients, long eye and nasal-inferior staphyloma. Safety and efficacy indexes were larger than 1.0 in all cases. However, we have found statistically significant better outcomes for the long eye group compared with the nasal-inferior staphyloma group (both UDVA and CDVA, see Table 2, $\mathrm{p}<0.01$ ). About 1 line of better visual acuity is found in long eyes. Focusing on the post-surgery cumulative CDVA, the long eye group showed an $80 \%$ of eyes (20) with 20/20 and the nasal-inferior staphyloma group a low percentage: $20 \%$ (5 eyes). Long eyes achieved a $100 \%$ of eyes with the same cumulative CDVA in 20/25 and nasal-inferior staphyloma eyes achieved this percentage in a low value: 20/32 (see Figure 2C). In relation to the postoperative mean sphere and cylinder, all values reported were less than a quarter of diopter (see Table 2), and we did not find statistically significant differences between groups $(p>0.1)$. Postoperative spherical equivalent accuracy was good for both groups (see Figure 2D). Appropriate IOL power selection based on accurate axial length and curvature measurements achieves the expected postoperative refraction.

Specifically, when the nasal-inferior staphyloma group was analysed as a function of the tilt, we found statistically significant better CDVA for the $<30$ degrees group (0.93) than for the $>30$ degrees group $(0.79, \mathrm{p}<0.01)$. Figure $2 \mathrm{~B}$ shows better outcomes for the $<30$ degrees subgroup indicating that larger values of tilt are associated with worse CDVA.

Previous studies using different IOL models in high myopic eyes showed good outcomes. Unfortunately, there are no previous studies using trifocal IOLs in this type of patients since publications of other authors have been done with bifocal lenses. However, its interesting to analyze these studies and compare with those found in our series of patients. For example, Alfonso et $\mathrm{al}^{12}$ and Wang et $\mathrm{al}^{13}$ assessed patients implanted with the AcrySof ReSTOR IOL at 6 months post-surgery. Alfonso et $\mathrm{al}^{12}$ using the SN60D3 lens in 76 high myopic eyes showed a CDVA of $20 / 40$ or better in $96 \%$ of eyes and $20 / 25$ or better in $88.1 \%$ of eyes. The mean logMAR CDVA was 0.05 and the IOL power implanted ranged from 10 to $14.50 \mathrm{D}$ (mean 12.09D). Wang et $\mathrm{al}^{13}$ reported the same postoperative mean $\log$ MAR CDVA (0.05) in two groups of eyes implanted with the SN6AD3 and SN6AD1 lenses (24 eyes each group, with 6.5-14 D IOL power range and a mean value of $11.19 \pm 2.15 \mathrm{D}$ and $11.9 \pm 1.52 \mathrm{D}$, respectively). They found that all eyes had a CDVA of 20/25 or better.

Martiano and Cochener ${ }^{14}$ evaluated 53 high myopic eyes using another lens at 6 years post-surgery: the AT LISA IOL. This bifocal IOL, with a 65/35-distribution percentage of energy, provided a mean logMAR CDVA of 0.08 and a CDVA of $20 / 25$ or better in $73 \%$ of eyes. Axial length in these eyes ranged from 26.54 to $30.7 \mathrm{~mm}$, with a mean value of $28.5 \pm 1.5 \mathrm{~mm}$, and IOL power ranged from 0 to $14 \mathrm{D}$, with a mean value of $10.5 \pm 0.71 \mathrm{D}$. Slight differences between studies may come from the use of a different multifocal IOL, different follow-up, and also for being higher myopic eyes in the case of Martiano and Cochener. $^{14}$

Ogawa et $\mathrm{al}^{15}$ analyzed the 12-month postoperative outcomes found in 32 eyes implanted with the ZMA00 or the ZMB00 IOL. The mean axial length in this group was $27.38 \mathrm{~mm}$, ranging from 26.06 to $29.24 \mathrm{~mm}$. Mean CDVA obtained in this study was $-0.15 \pm 0.06 \operatorname{logMAR}$. And, Zhu et $\mathrm{al}^{16}$ found in 28 eyes, with axial length $>24.5 \mathrm{~mm}$, implanted with the ZMB00 IOL, a mean CDVA value of $0.05 \pm 0.06 \log$ MAR. Note that in this study the mean axial length was $25.44 \pm 1.04 \mathrm{~mm}, 2 \mathrm{~mm}$ shorter than the Ogawa et $\mathrm{al}^{15}$ study. Again, when we compare studies, a different IOL design may play a role when obtaining different visual outcomes.

In the present study, we have included eyes with a mean axial length of $27.59 \pm 1.08 \mathrm{~mm}$ and 27.94 $\pm 0.99 \mathrm{~mm}$, for the long eye and nasal-inferior staphyloma group, respectively (mean IOL power of 9.78 $\pm 3.59 \mathrm{D}$ and $7.73 \pm 3.10 \mathrm{D}$, respectively). Our study has been carried out with higher myopic eyes compared with previous literature. Despite this, the outcomes reported revealed comparable CDVA (see Table 2). Taking into account our findings, we consider that a trifocal IOL may be used to be implanted in high myopic eyes. However, eyes diagnosed with nasal-inferior staphyloma showed worse outcomes than long eyes with similar axial length. In this group of eyes, those with higher macula plane tilt $(>30$ degrees) show worse outcomes compared with lower tilt ( $<30$ degrees). Then, if we consider that the light distribution is different between bifocal and trifocal IOLs (two foci: $50 / 50$ or $65 / 35$ versus thee foci: 50/20/30), those patients diagnosed with nasal-inferior staphyloma may benefit more using bifocal (65/35) than trifocal IOLs. A higher percentage of light on the far focus may provide 
better distance visual acuity. Then, clinicians should be aware of the present outcomes in order to choose the best IOL in this type of patients.

This preliminary study reveals that high myopic eyes diagnosed with nasal-inferior staphyloma may be implanted with trifocal lenses, but better outcomes may be expected with bifocals asymmetric (65/35), especially in those eyes with higher macular plane tilt. Future studies should focus on the use of different IOL models in patients diagnosed with different types of staphyloma. A good preoperative evaluation that focuses on macular region becomes extremely important to select an appropriate multifocal IOL and consequently achieve good visual performance.

\section{Disclosure}

The authors have no proprietary interest in any of the materials mentioned in this article and report no conflicts of interest in this work.

\section{References}

1. Wu P-C, Huang H-M, Yu H-J, Fang P-C, Chen C-T. Epidemiology of myopia. Asia Pac J Ophthalmol (Phila). 2016;5:386-393. doi:10.1097/APO.0000000000000236

2. Hsiang HW, Ohno-Matsui K, Shimada N, et al. Clinical characteristics of posterior staphyloma in eyes with pathologic myopia. $\mathrm{Am}$ J Ophthalmol. 2008;146:102-110. doi:10.1016/j.ajo.2008.03.010

3. Ikuno Y, Jo Y, Hamasaki T, Tano Y. Ocular risk factors for choroidal neovascularization in pathologic myopia. Invest Ophthalmol Vis Sci. 2010;51:3721-3725. doi:10.1167/iovs.09-3493

4. Vongphanit J, Mitchell P, Wang JJ. Prevalence and progression of myopic retinopathy in an older population. Ophthalmology. 2002;109:704-711. doi:10.1016/S0161-6420(01)01024-7

5. Gao LQ, Liu W, Liang YB, et al. Prevalence and characteristics of myopic retinopathy in a rural Chinese adult population: the Handan Eye Study. Arch Ophthalmology. 2011;129:1199-1204. doi:10.1001/ archophthalmol.2011.230

6. Liu HH, Xu L, Wang YX, Wang S, You QS, Jonas JB. Prevalence and progression of myopic retinopathy in Chinese adults: the Beijing Eye Study. Ophthalmology. 2010;117:1763-1768. doi:10.1016/j.ophtha.20 10.01.020
7. Samarawickrama C, Mitchell P, Tong L, et al. Myopic-related optic disc and retinal changes in adolescent children from Singapore. Ophthalmology. 2011;118:2050-2057. doi:10.1016/j.ophtha.2011. 02.040

8. Edge R, Navon S. Axial length and posterior staphyloma in Saudi Arabian cataract patients. J Cataract Refract Surg. 1999;25:91-95. doi:10.1016/S0886-3350(99)80017-0

9. Numa S, Yamashiro K, Wakazono T, et al. Prevalence of posterior staphyloma and factors associated with its shape in the Japanese population. Sci Rep. 2018;8:4594. doi:10.1038/s41598-018-22759-y

10. Younan C, Mitchell P, Cumming RG, Rochtchina E, Wang JJ. Myopia and incident cataract and cataract surgery: the blue mountains eye study. Invest Ophthalmol Vis Sci. 2002;43:3625-3632.

11. Kanthan GL, Mitchell P, Rochtchina E, Cumming RG, Wang JJ. Myopia and the long-term incidence of cataract and cataract surgery: the Blue Mountains Eye Study. Clin Exp Ophthalmol. 2014;42:347-353. doi:10.1111/ceo.2014.42.issue-4

12. Alfonso JF, Fernández-Vega L, Ortí S, Ferrer-Blasco T, Montés-Micó R. Differences in visual performance of AcrySof ReSTOR IOL in high and low myopic eyes. Eur J Ophthalmol. 2010;20:333-339. doi:10.1177/112067211002000212

13. Wang Q, Zhao G, Wang Q, Jia W. Visual quality after AcrySof IQ ReSTOR intraocular lens implantation in eyes with high myopia. Eur J Ophthalmol. 2012;22:168-174. doi:10.5301/EJO.2011.8357

14. Martiano D, Cochener B. Multifocal IOLs in the high myope, 6-year follow-up. $J$ Fr Ophtalmol. 2014;37:393-399. doi:10.1016/j.jfo. 2013.08.009

15. Ogawa T, Shiba T, Tsuneoka H. Usefulness of implantation of diffractive multifocal intraocular lens in eyes with long axial lengths. J Ophthalmol. 2015;2015:956046.

16. Zhu X, He W, Zhang Y, Chen M, Du Y, Lu Y. Inferior decentration of multifocal intraocular lenses in myopic eyes. Am J Ophthalmol. 2018;188:1-8. doi:10.1016/j.ajo.2018.01.007

17. Curtin BJ. The posterior staphyloma of pathologic myopia. Trans Am Ophthalmol Soc. 1977;75:67-86.

18. Ohno-Matsui K. Proposed classification of posterior staphylomas based on analyses of eye shape by three-dimensional magnetic resonance imaging. Ophthalmology. 2014;121:1798-1809. doi:10.1016/j. ophtha.2014.03.035

19. Shinohara K, Shimada N, Moriyama M, et al. Posterior staphylomas in pathologic myopia imaged by widefield optical coherence tomography. Invest Ophthalmol Vis Sci. 2017;58:3750-3758. doi:10.1167/iovs.17-22319

20. Srinivasan B, Leung HY, Cao H, Liu S, Chen L, Fan AH. Modern phacoemulsification and intraocular lens implantation (Refractive lens exchange) is safe and effective in treating high myopia. Asia Pac J Ophthalmol (Phila). 2016;5:438-444. doi:10.1097/APO.00000 00000000241
Clinical Ophthalmology

\section{Publish your work in this journal}

Clinical Ophthalmology is an international, peer-reviewed journal covering all subspecialties within ophthalmology. Key topics include: Optometry; Visual science; Pharmacology and drug therapy in eye diseases; Basic Sciences; Primary and Secondary eye care; Patient Safety and Quality of Care Improvements. This journal is indexed on PubMed
Central and CAS, and is the official journal of The Society of Clinical Ophthalmology (SCO). The manuscript management system is completely online and includes a very quick and fair peer-review system, which is all easy to use. Visit http://www.dovepress.com/ testimonials.php to read real quotes from published authors. 